\title{
PD-L1 is an independent prognostic predictor in gastric cancer of Western patients
}

\author{
Christine Böger ${ }^{1}$, Hans-Michael Behrens ${ }^{1}$, Micaela Mathiak ${ }^{1}$, Sandra Krüger ${ }^{1}$, \\ Holger Kalthoff ${ }^{2}$, Christoph Röcken ${ }^{1}$ \\ ${ }^{1}$ Department of Pathology, Christian-Albrechts-University, Kiel, Germany \\ ${ }^{2}$ Department of Experimental Cancer Research, Christian-Albrechts-University, Kiel, Germany \\ Correspondence to: Christoph Röcken, e-mail: christoph.roecken@uksh.de
}

Keywords: programmed death-1, predictive biomarker, immune therapy, pembrolizumab

Received: February 03, 2016 Accepted: March 02, $2016 \quad$ Published: March 18, 2016

\section{ABSTRACT}

Targeting the PD-1/PD-L1 immune checkpoint signaling is a novel promising treatment strategy in several tumor entities, and it is suggested that PD-L1/PD-1 expression is predictive for a PD-1/PD-L1 checkpoint inhibitor treatment response. We investigated the expression of PD-L1 and PD-1 by immunohistochemistry in a large and well characterized gastric cancer (GC) cohort of Caucasian patients, consisting of 465 GC samples and 15 corresponding liver metastases. Staining results were correlated with clinico-pathological characteristics and survival. PD-L1 expression was found in tumor cells of $140 \mathrm{GCs}(30.1 \%)$ and 9 liver metastases $(60 \%)$ respectively in immune cells of 411 GCs (88.4\%) and 11 liver metastases (73.3\%). PD-1 was expressed in tumor infiltrating lymphocytes in $250 \mathrm{GCs}(53.8 \%)$ and in 11 liver metastases (73.3\%). PD-L1 expression was significantly more prevalent in men, GCs of the proximal stomach, unclassified, papillary, Her2/neu-positive, Epstein-Barrvirus-positive, microsatellite instable, and PIK3CA-mutated GCs. A high PD-L1/PD-1 expression was associated with a significantly better patient outcome, and PD-L1 turned out to be an independent survival prognosticator. The correlation of PD-L1/ PD-1 expression with distinct clinico-pathological patient characteristics may serve as a surrogate marker of PD-L1-positive GCs and may direct the use of immune checkpoint treatment strategies.

\section{INTRODUCTION}

The genetic complexity of gastric cancer (GC) has been recently shown in an integrative genomic analysis including whole-genome sequencing. A molecular classification was proposed, which categorizes four subtypes, i.e. Epstein-Barr-virus (EBV)-positive, microsatellite instable (MSI), chromosomal instable, and genomically stable GCs $[1,2]$. These current findings serve as a roadmap for patient stratification and trials of targeted therapies, and it turned out that elevated PD-L1 expression was enriched in EBV-positive and MSI GCs.

PD-L1 (B7-H1) is a 290aa type I transmembrane surface glycoprotein encoded by the CD274 gene located on chromosome 9 and expressed by several cell types of the immune system, e.g. lymphocytes and dendritic cells, but also aberrantly on the surface of epithelial cells of a wide range of solid tumors. PD-L1 is the ligand of programmed cell death 1 (PD-1), which is a member of the immunoglobulin superfamily B7 and involved in immunomodulation [3]. PD-1 is known to be expressed by activated T-cells on the germinal center of lymph follicles, but also on tumor infiltrating lymphocytes (TILs) and other immune cells [4]. The interaction of PD-1 with its ligand PD-L1 induces a suppression of T-cell receptor signaling and results in a down regulation of the immune response, which enables cancer cells to escape immune destruction [5]. Therapeutic PD-1/PD-L1 checkpoint inhibitors target the PD-1/PD-L1 immune checkpoint in order to restore the cancer cell-directed immune response [6].

Currently, more than 400 studies worldwide focus on PD-L1/PD-1 immune checkpoint signaling, including 65 studies for cancer of the gastrointestinal tract [7], and there is some evidence that PD-L1 expression is associated 
with response to PDL-1/PD-1 pathway inhibition [8]. Preliminary results in metastatic GC with PD-1/PD-L1 checkpoint inhibitors are highly promising, and phase III studies have recently started [9]. To date, the PD-L1/ PD-1 in GC was only evaluated in small cohorts of Asian patients, but not in Caucasians, whose GCs are known to hold different gene signatures [10]. Thus, data regarding the expression and impact of PD-L1/PD-1 in GC in Western patients is urgently needed, but not yet available. In order to fill this gap of information, we systematically investigated the expression of PD-L1 and PD-1 in a large and thoroughly characterized Central European GC cohort.

\section{RESULTS}

The clinico-pathological characteristics of our patient cohort are summarized in Table 1. 465 patients fulfilled all study criteria. Overall survival data was available in $451(97.0 \%)$ cases, tumor specific survival data in $421(90.5 \%)$. Mean follow-up period was 20.7 months (range 0.2 to 109.0 months).

\section{PD-L1 and PD-1 expression}

\section{PD-L1}

PD-L1 expression was observed in tumor, stromal and immune cells, but not in non-neoplastic gastric epithelium. 140 of 465 cases (30.1\%) showed a membranous PD-L1 expression in tumor cells. The percentage of stained tumor cells ranged from 0 to $80 \%$ (median $0 \%$ ), the staining intensity ranged from 0 to 3 (median 0; Figure 1A-1C; Table 1). Only a minority of cases showed different staining intensities within the same tumor. Although we aimed for the HistoScore, we recognized that the overall percentage of PD-L1positive tumor cells was low (in $90 \%$ of the cases $<10 \%$ immunopositive tumor cells; Table 2) and assessment of different percentages of three different staining intensities was indiscernible and impractical. Therefore, the application of the HistoScore was discarded and a simplified IRS was applied [11]. The tumor cell IRS ranged from 0 to 7 (median 0 ). Dichotomized by an IRS of 2, 111 cases $(23.9 \%)$ were classified as positive and 354 cases (76.1\%) as negative (Table 2; Figure 2). Additionally, intratumoral necrosis with a membranous PD-L1 staining of necrotic tumor cells was found in 72 of 465 cases $(15.5 \%$; Figure $1 \mathrm{~K})$. Statistical analysis was carried out only for staining of vital tumor cells.

PD-L1 expression in immune cells was found in 411 of 465 cases $(88.4 \%$ ) also serving as a positive control for the negatively rated tumor cell cases. The percentage of stained immune cells ranged from 0 to $70 \%$ (median $5 \%$ ), the intensity ranged from 0 to 3 (median 1). As the majority of cases with PD-L1 positive immune cells showed a weak staining intensity (302 of 411 cases, $73.5 \%$ ), the intensity of the immunostaining was neglected for further statistical analyses, and only the percentage of PD-L1 positive immune cells was considered. All cases were graded into four groups as 0 (negative), 1 (1-9\% positive), 2 (10-20\% positive), and 3 ( $>20 \%$ positive). For further statistical analyses, group 0 and 1 were summarized and classified as "PD-L1 negative in immune cells" (300 of 465 cases, 64.5\%), and group 2 and 3 were classified "PD-L1 positive in immune cells" (165 of 465 cases, 35.5\%).

The PD-L1 expression in stroma cells was mainly very limited to single cells, hence only the presence or absence was evaluated; PD-L1 positive stroma cells were observed in 107 of 465 cases (23.0\%; Figure 1L).

\section{PD-L1 expression patterns}

EBV-positive GCs and MSI-carcinomas of other origin (e.g. colorectal) are known to be associated with PD-L1 overexpression $[1,14,15]$. Next we correlated the PD-L1/PD-1 staining results with the previously assessed EBV- and MSI-status and the Laurén- and WHOphenotype (Table $1 \& 2$ ). PD-L1 expression in tumor cells was observed significantly more often, more intense and more extensive in EBV-positive, MSI, papillary type, and unclassified GCs ( $<<0.001$ each; Table 2). Especially MSI-GCs with peculiar histologic MSI features [10] often showed a high PD-L1 expression in tumor cells (Table 2).

Moreover, four different PD-L1 expression patterns were observed: (1) EBV-positive GCs often showed a heterogeneous, "patchy" expression pattern with a striking accumulation of PD-L1 positive tumor cells around larger blood vessels. (2) MSI-GCs were mainly PD-L1positive at the interface between neoplastic and nonneoplastic tissue, especially in areas of "pushing borders". (3) Papillary type GCs often showed PD-L1 positivity within the fibrovascular connective tissue cores and the intratumoral necrosis. (4) Other cases mainly showed no distinct PD-L1 distribution pattern and were classified as "patternless" (Supplementary File 1).

\section{PD-1}

PD-1 expression was observed neither in tumor nor stroma cells. PD-1 positive diffusely distributed TILs were present in 250 of 465 cases $(53.8 \%)$. As the amount of PD-1 positive TILs was mainly restricted to single cells, a quantitative analysis was neglected. Apart from a cumulative appearance of PD-1 positive immune cells in intratumoral lymphocyte aggregates/lymph follicles (413 of 465 cases; $88.8 \%$; Figure $1 \mathrm{G}$ ), no distinct distribution pattern was observed. PD-1 expression in TILs was significantly correlated with PD-L1 expression in tumor, stroma and immune cells ( $\mathrm{p}<0.001$ each; Figure $1 \mathrm{H})$. 
Table 1: Clinico-pathological patient characteristics and their correlation with PD-L1 and PD-1 expression

\begin{tabular}{|c|c|c|c|c|c|c|c|c|c|c|c|c|c|c|}
\hline & \multicolumn{2}{|c|}{ Total Valid } & \multicolumn{4}{|c|}{ PD-L1 in Tumor Cells } & \multicolumn{4}{|c|}{ PD-L1 in Immune Cells } & \multicolumn{4}{|c|}{ PD-1 in Immune Cells } \\
\hline & \multirow[b]{3}{*}{ n } & \multirow[b]{3}{*}{$(\%)$} & \multirow{2}{*}{\multicolumn{2}{|c|}{ negative }} & \multicolumn{2}{|r|}{ p-value } & \multirow{2}{*}{\multicolumn{2}{|c|}{ negative }} & \multirow{2}{*}{\multicolumn{2}{|c|}{$\begin{array}{l}\text { p-value } \\
\text { positive }\end{array}$}} & \multirow{2}{*}{\multicolumn{2}{|c|}{ negative }} & \multirow{2}{*}{\multicolumn{2}{|c|}{$\begin{array}{l}\text { p-value } \\
\text { positive }\end{array}$}} \\
\hline & & & & & & tive & & & & & & & & \\
\hline & & & n & $(\%)$ & $\mathbf{n}$ & $(\%)$ & n & $(\%)$ & $\mathbf{n}$ & $(\%)$ & n & $(\%)$ & n & $(\%)$ \\
\hline Gender & 465 & & & & & 0.018 & & & & 0.319 & & & & 0.848 \\
\hline Female & 175 & $(37.6)$ & 144 & $(82.3)$ & 31 & $(17.7)$ & 118 & $(67.4)$ & 57 & $(32.6)$ & 82 & $(46.9)$ & 93 & $(53.1)$ \\
\hline Male & 290 & $(62.4)$ & 210 & $(72.4)$ & 80 & $(27.6)$ & 182 & $(62.8)$ & 108 & $(37.2)$ & 133 & $(45.9)$ & 157 & $(54.1)$ \\
\hline Age Group & 465 & & & & & 0.588 & & & & 0.245 & & & & 0.710 \\
\hline$<68$ years & 232 & $(49.9)$ & 174 & $(75.0)$ & 58 & $(25.0)$ & 156 & $(67.2)$ & 76 & $(32.8)$ & 105 & $(45.3)$ & 127 & $(54.7)$ \\
\hline$\geq 68$ years & 233 & $(50.1)$ & 180 & $(77.3)$ & 53 & $(22.7)$ & 144 & (61.8) & 89 & $(38.2)$ & 110 & $(47.2)$ & 123 & $(52.8)$ \\
\hline Localization & 460 & & & & & $<0.001$ & & & & 0.248 & & & & 481 \\
\hline Proximal & 145 & $(31.5)$ & 95 & $(65.5)$ & 50 & $(34.5)$ & 88 & $(60.7)$ & 57 & (39.3) & 63 & $(43.4)$ & 82 & $(56.6)$ \\
\hline Distal & 315 & $(68.5)$ & 256 & $(81.3)$ & 59 & (18.7) & 210 & (66.7) & 105 & (33.3) & 149 & (47.3) & 166 & $(52.7)$ \\
\hline $\begin{array}{l}\text { Laurén } \\
\text { Phenotype }\end{array}$ & 464 & & & & & $<0.001$ & & & & 0.089 & & & & 0.057 \\
\hline Intestinal & 240 & $(51.7)$ & 170 & (70.8) & 70 & $(29.2)$ & 150 & $(62.5)$ & 90 & $(37.5)$ & 105 & $(43.8)$ & 135 & $(56.2)$ \\
\hline Diffuse & 145 & (31.3) & 136 & (93.8) & 9 & (6.2) & 101 & (69.7) & 44 & $(30.3)$ & 78 & $(53.8)$ & 67 & $(46.2)$ \\
\hline Mixed & 31 & (6.7) & 27 & $(87.1)$ & 4 & (12.9) & 23 & $(74.2)$ & 8 & $(25.8)$ & 16 & $(51.6)$ & 15 & $(48.4)$ \\
\hline Unclassified & 48 & (10.3) & 20 & $(41.7)$ & 28 & $(58.3)$ & 25 & $(52.1)$ & 23 & (47.9) & 16 & (33.3) & 32 & $(66.7)$ \\
\hline $\begin{array}{l}\text { Mucin } \\
\text { Phenotype }\end{array}$ & 408 & & & & & 0.014 & & & & 0.798 & & & & 0.553 \\
\hline Intestinal & 118 & (28.9) & 77 & $(65.3)$ & 41 & $(34.7)$ & 78 & $(66.1)$ & 40 & (33.9) & 56 & $(47.5)$ & 62 & $(52.5)$ \\
\hline Gastric & 64 & $(15.7)$ & 51 & (79.7) & 13 & (20.3) & 40 & $(62.5)$ & 24 & $(37.5)$ & 31 & $(48.4)$ & 33 & $(51.6)$ \\
\hline Mixed & 157 & $(38.5)$ & 128 & $(81.5)$ & 29 & (18.5) & 102 & $(65.0)$ & 55 & $(35.0)$ & 71 & $(45.2)$ & 86 & $(54.8)$ \\
\hline Unclassified & 69 & $(16.9)$ & 55 & $(79.7)$ & 14 & $(20.3)$ & 41 & $(59.4)$ & 28 & $(40.6)$ & 26 & $(37.7)$ & 43 & $(62.3)$ \\
\hline T-Category & 463 & & & & & 0.001 & & & & 0.005 & & & & 0.932 \\
\hline T1a & 11 & (2.4) & 11 & (100.0) & 0 & $(0.0)$ & 10 & (90.9) & 1 & $(9.1)$ & 6 & $(54.5)$ & 5 & $(45.5)$ \\
\hline $\mathrm{T} 1 \mathrm{~b}$ & 44 & $(9.5)$ & 35 & (79.5) & 9 & $(20.5)$ & 30 & $(68.2)$ & 14 & (31.8) & 20 & $(45.5)$ & 24 & $(54.5)$ \\
\hline $\mathrm{T} 2$ & 54 & (11.7) & 28 & (51.9) & 26 & $(48.1)$ & 23 & $(42.6)$ & 31 & $(57.4)$ & 22 & $(40.7)$ & 32 & $(59.3)$ \\
\hline $\mathrm{T} 3$ & 186 & $(40.2)$ & 149 & $(80.1)$ & 37 & (19.9) & 118 & (63.4) & 68 & (36.6) & 88 & $(47.3)$ & 98 & $(52.7)$ \\
\hline $\mathrm{T} 4 \mathrm{a}$ & 128 & $(27.6)$ & 99 & $(77.3)$ & 29 & $(22.7)$ & 88 & (68.8) & 40 & $(31.2)$ & 58 & (45.3) & 70 & $(54.7)$ \\
\hline $\mathrm{T} 4 \mathrm{~b}$ & 40 & (8.6) & 30 & $(75.0)$ & 10 & $(25.0)$ & 29 & $(72.5)$ & 11 & $(27.5)$ & 20 & $(50.0)$ & 20 & $(50.0)$ \\
\hline N-Category & 462 & & & & & 0.412 & & & & 0.223 & & & & 0.106 \\
\hline No & 132 & $(28.6)$ & 97 & $(73.5)$ & 35 & $(26.5)$ & 76 & $(57.6)$ & 56 & $(42.4)$ & 57 & $(43.2)$ & 75 & $(56.8)$ \\
\hline N1 & 67 & (14.5) & 47 & $(70.1)$ & 20 & (29.9) & 48 & (71.6) & 19 & $(28.4)$ & 34 & $(50.7)$ & 33 & (49.3) \\
\hline $\mathrm{N} 2$ & 81 & $(17.5)$ & 63 & (77.8) & 18 & $(22.2)$ & 54 & $(66.7)$ & 27 & $(33.3)$ & 46 & $(56.8)$ & 35 & $(43.2)$ \\
\hline $\mathrm{N} 3(\mathrm{a} / \mathrm{b})$ & 182 & (39.4) & 144 & (79.1) & 38 & (20.9) & 119 & $(65.4)$ & 63 & $(34.6)$ & 76 & $(41.8)$ & 106 & $(58.2)$ \\
\hline M-Category & 465 & & & & & $0.029^{(1)}$ & & & & $<0.001$ & & & & 0.641 \\
\hline M0 & 373 & $(80.2)$ & 276 & $(74.0)$ & 97 & $(26.0)$ & 226 & $(60.6)$ & 147 & $(39.4)$ & 170 & $(45.6)$ & 203 & $(54.4)$ \\
\hline M1 & 92 & (19.8) & 78 & (84.8) & 14 & (15.2) & 74 & $(80.4)$ & 18 & (19.6) & 45 & (48.9) & 47 & $(51.1)$ \\
\hline
\end{tabular}

(Continued) 


\begin{tabular}{|c|c|c|c|c|c|c|c|c|c|c|c|c|c|c|}
\hline & \multicolumn{2}{|c|}{ Total Valid } & \multicolumn{4}{|c|}{ PD-L1 in Tumor Cells } & \multicolumn{4}{|c|}{ PD-L1 in Immune Cells } & \multicolumn{4}{|c|}{ PD-1 in Immune Cells } \\
\hline & \multirow[b]{3}{*}{$\mathbf{n}$} & \multirow[b]{3}{*}{$(\%)$} & \multirow{2}{*}{\multicolumn{2}{|c|}{ negative }} & \multicolumn{2}{|r|}{ p-value } & \multirow{2}{*}{\multicolumn{2}{|c|}{ negative }} & \multirow{2}{*}{\multicolumn{2}{|c|}{$\begin{array}{l}\text { p-value } \\
\text { positive }\end{array}$}} & \multirow{2}{*}{\multicolumn{2}{|c|}{ negative }} & \multirow{2}{*}{\multicolumn{2}{|c|}{$\begin{array}{l}\text { p-value } \\
\text { positive }\end{array}$}} \\
\hline & & & & & & tive & & & & & & & & \\
\hline & & & n & $(\%)$ & $\mathbf{n}$ & $(\%)$ & $\mathbf{n}$ & $(\%)$ & $\mathbf{n}$ & $(\%)$ & n & $(\%)$ & $\mathbf{n}$ & $(\%)$ \\
\hline $\begin{array}{l}\text { Liver } \\
\text { Metastases }\end{array}$ & 465 & & & & & 1.000 & & & & 0.439 & & & & 0.460 \\
\hline no & 448 & $(96.3)$ & 341 & $(76.1)$ & 107 & $(23.9)$ & 287 & $(64.1)$ & 161 & $(35.9)$ & 209 & $(46.7)$ & 239 & $(53.3)$ \\
\hline yes & 17 & $(3.7)$ & 13 & $(76.5)$ & 4 & $(23.5)$ & 13 & $(76.5)$ & 4 & $(23.5)$ & 6 & $(35.3)$ & 11 & $(64.7)$ \\
\hline UICC-Stage & 463 & & & & & 0.010 & & & & 0.001 & & & & 0.855 \\
\hline IA & 44 & $(9.5)$ & 37 & $(84.1)$ & 7 & $(15.9)$ & 31 & $(70.5)$ & 13 & $(29.5)$ & 20 & $(45.5)$ & 24 & $(54.5)$ \\
\hline IB & 34 & (7.3) & 21 & $(61.8)$ & 13 & $(38.2)$ & 16 & $(47.1)$ & 18 & $(52.9)$ & 14 & $(41.2)$ & 20 & $(58.8)$ \\
\hline IIA & 57 & (12.3) & 42 & (73.7) & 15 & $(26.3)$ & 34 & $(59.6)$ & 23 & $(40.4)$ & 27 & $(47.4)$ & 30 & $(52.6)$ \\
\hline IIB & 45 & $(9.7)$ & 28 & $(62.2)$ & 17 & $(37.8)$ & 29 & $(64.4)$ & 16 & $(35.6)$ & 19 & $(42.2)$ & 26 & $(57.8)$ \\
\hline IIIA & 52 & $(11.2)$ & 35 & $(67.3)$ & 17 & $(32.7)$ & 30 & (57.7) & 22 & $(42.3)$ & 29 & $(55.8)$ & 23 & $(44.2)$ \\
\hline IIIB & 80 & (17.3) & 67 & $(83.8)$ & 13 & $(16.2)$ & 42 & $(52.5)$ & 38 & $(47.5)$ & 35 & $(43.8)$ & 45 & $(56.2)$ \\
\hline IIIC & 61 & $(13.2)$ & 46 & $(75.4)$ & 15 & $(24.6)$ & 44 & $(72.1)$ & 17 & $(27.9)$ & 26 & $(42.6)$ & 35 & $(57.4)$ \\
\hline IV & 90 & (19.4) & 76 & $(84.4)$ & 14 & $(15.6)$ & 72 & $(80.0)$ & 18 & $(20.0)$ & 44 & (48.9) & 46 & $(51.1)$ \\
\hline $\begin{array}{l}\text { Lymph Node } \\
\text { Ratio }\end{array}$ & 461 & & & & & 0.016 & & & & 0.174 & & & & 0.852 \\
\hline$<$ Median & 227 & $(49.2)$ & 161 & (70.9) & 66 & $(29.1)$ & 139 & $(61.2)$ & 88 & $(38.8)$ & 106 & (46.7) & 121 & (53.3) \\
\hline$\geq$ Median & 234 & $(50.8)$ & 189 & $(80.8)$ & 45 & $(19.2)$ & 158 & $(67.5)$ & 76 & $(32.5)$ & 107 & $(45.7)$ & 127 & $(54.3)$ \\
\hline L-Category & 461 & & & & & 0.146 & & & & 0.005 & & & & 0.849 \\
\hline L0 & 216 & $(48.8)$ & 158 & $(73.1)$ & 58 & $(26.9)$ & 125 & (57.9) & 91 & $(42.1)$ & 99 & $(45.8)$ & 117 & $(54.2)$ \\
\hline L1 & 227 & $(51.2)$ & 180 & (79.3) & 47 & $(20.7)$ & 161 & (70.9) & 66 & $(29.1)$ & 107 & $(47.1)$ & 120 & $(52.9)$ \\
\hline V-Category & 442 & & & & & 0.595 & & & & 0.113 & & & & 0.069 \\
\hline V0 & 393 & $(88.9)$ & 302 & $(76.8)$ & 91 & $(23.2)$ & 249 & $(63.4)$ & 144 & $(36.6)$ & 177 & $(45.0)$ & 216 & $(55.0)$ \\
\hline V1 & 49 & (11.1) & 36 & $(73.5)$ & 13 & $(26.5)$ & 37 & $(75.5)$ & 12 & $(24.5)$ & 29 & $(59.2)$ & 20 & $(40.8)$ \\
\hline Grade & 463 & & & & & 0.377 & & & & 0.652 & & & & 0.450 \\
\hline $\mathrm{G} 1 / \mathrm{G} 2$ & 114 & (24.6) & 83 & (72.8) & 31 & $(27.2)$ & 71 & $(62.3)$ & 43 & $(37.7)$ & 49 & $(43.0)$ & 65 & $(57.0)$ \\
\hline G3/G4 & 349 & $(75.4)$ & 269 & $(77.1)$ & 80 & $(22.9)$ & 227 & $(65.0)$ & 122 & $(35.0)$ & 165 & $(47.3)$ & 184 & $(52.7)$ \\
\hline R-Status & 463 & & & & & 0.138 & & & & 0.141 & & & & 0.574 \\
\hline $\mathrm{R} 0$ & 401 & $(87.4)$ & 301 & $(75.1)$ & 100 & $(24.9)$ & 254 & $(63.3)$ & 147 & $(36.7)$ & 183 & $(45.6)$ & 218 & $(54.4)$ \\
\hline $\mathrm{R} 1 / \mathrm{R} 2$ & 58 & (12.6) & 49 & $(84.5)$ & 9 & $(15.5)$ & 43 & (74.1) & 15 & $(25.9)$ & 29 & $(50.0)$ & 29 & $(50.0)$ \\
\hline $\begin{array}{l}\text { H. pylori- } \\
\text { status }\end{array}$ & 392 & & & & & 0.625 & & & & 0.665 & & & & 0.126 \\
\hline Negative & 331 & $(84.4)$ & 254 & $(76.7)$ & 77 & $(23.3)$ & 212 & $(64.0)$ & 119 & $(36.0)$ & 155 & $(46.8)$ & 176 & $(53.2)$ \\
\hline Positive & 61 & (15.6) & 45 & (73.8) & 16 & $(26.2)$ & 37 & $(60.7)$ & 24 & $(39.3)$ & 22 & $(36.1)$ & 39 & $(63.9)$ \\
\hline EBV-Status & 451 & & & & & $<0.001$ & & & & 0.003 & & & & $0.021^{(1)}$ \\
\hline Negative & 431 & (95.6) & 338 & (78.4) & 93 & $(21.6)$ & 281 & $(65.2)$ & 150 & $(34.8)$ & 203 & $(47.1)$ & 228 & $(52.9)$ \\
\hline Positive & 20 & (4.4) & 2 & $(10.0)$ & 18 & $(90.0)$ & 6 & $(30.0)$ & 14 & $(70.0)$ & 4 & $(20.0)$ & 16 & $(80.0)$ \\
\hline MSI-Status & 450 & & & & & 0.001 & & & & 0.282 & & & & 0.606 \\
\hline MSS & 414 & $(92.0)$ & 321 & $(77.5)$ & 83 & $(22.5)$ & 268 & $(64.7)$ & 146 & $(35.3)$ & 188 & $(45.4)$ & 226 & $(54.6)$ \\
\hline MSI & 36 & $(8.0)$ & 18 & $(50.0)$ & 18 & $(50.0)$ & 20 & (55.6) & 16 & $(44.4)$ & 18 & $(50.0)$ & 18 & $(50.0)$ \\
\hline
\end{tabular}

(Continued) 


\begin{tabular}{|c|c|c|c|c|c|c|c|c|c|c|c|c|c|c|}
\hline & \multicolumn{2}{|c|}{ Total Valid } & \multicolumn{4}{|c|}{ PD-L1 in Tumor Cells } & \multicolumn{4}{|c|}{ PD-L1 in Immune Cells } & \multicolumn{4}{|c|}{ PD-1 in Immune Cells } \\
\hline & \multirow[b]{3}{*}{$\mathbf{n}$} & \multirow[b]{3}{*}{$(\%)$} & \multirow{2}{*}{\multicolumn{2}{|c|}{ negative }} & \multirow{2}{*}{\multicolumn{2}{|c|}{ p-value }} & \multirow{2}{*}{\multicolumn{2}{|c|}{ negative }} & \multirow{2}{*}{\multicolumn{2}{|c|}{ p-value }} & \multirow{2}{*}{\multicolumn{2}{|c|}{ negative }} & \multirow{2}{*}{\multicolumn{2}{|c|}{$\begin{array}{l}\text { p-value } \\
\text { positive }\end{array}$}} \\
\hline & & & & & & & & & & & & & & \\
\hline & & & $\mathbf{n}$ & $(\%)$ & $\mathbf{n}$ & $(\%)$ & $\mathbf{n}$ & $(\%)$ & $\mathbf{n}$ & $(\%)$ & $\mathbf{n}$ & $(\%)$ & $\mathbf{n}$ & $(\%)$ \\
\hline $\begin{array}{l}\text { Her2/neu- } \\
\text { Status }\end{array}$ & 433 & & & & & 0.001 & & & & 0.596 & & & & $0.040^{(1)}$ \\
\hline Negative & 396 & $(91.5)$ & 307 & $(77.5)$ & 89 & $(22.5)$ & 253 & $(63.9)$ & 143 & $(36.1)$ & 188 & $(47.5)$ & 208 & $(52.5)$ \\
\hline Positive & 37 & $(8.5)$ & 19 & (51.4) & 18 & $(48.6)$ & 22 & $(59.5)$ & 15 & $(40.5)$ & 11 & (29.7) & 26 & $(70.3)$ \\
\hline MET-Status & 454 & & & & & 0.528 & & & & 0.704 & & & & 0.274 \\
\hline Negative & 422 & $(93.0)$ & 318 & $(75.4)$ & 104 & $(24.6)$ & 272 & $(64.5)$ & 150 & $(35.5)$ & 193 & (45.7) & 229 & $(54.3)$ \\
\hline Positive & 32 & $(7.0)$ & 26 & $(81.2)$ & 6 & (18.8) & 22 & $(68.8)$ & 10 & $(31.2)$ & 18 & $(56.2)$ & 14 & $(43.8)$ \\
\hline $\begin{array}{l}K R A S \text { - } \\
\text { Genotype }\end{array}$ & 457 & & & & & $0.031^{(1)}$ & & & & 0.595 & & & & 0.612 \\
\hline Wildtype & 441 & (96.5) & 339 & (76.9) & 102 & $(23.1)$ & 287 & $(65.1)$ & 154 & (34.9) & 207 & (46.9) & 234 & $(53.1)$ \\
\hline Mutated & 16 & (3.5) & 8 & $(50.0)$ & 8 & $(50.0)$ & 9 & (56.2) & 7 & (43.8) & 6 & $(37.5)$ & 10 & $(62.5)$ \\
\hline $\begin{array}{l}P I K 3 C A- \\
\text { Genotype }\end{array}$ & 457 & & & & & 0.006 & & & & 0.004 & & & & $0.012^{(1)}$ \\
\hline Wildtype & 436 & (95.4) & 337 & (77.3) & 99 & $(22.7)$ & 289 & (66.3) & 147 & (33.7) & 209 & (47.9) & 227 & $(52.1)$ \\
\hline Mutated & 21 & $(4.6)$ & 10 & $(47.6)$ & 11 & $(52.4)$ & 7 & (33.3) & 14 & $(66.7)$ & 4 & (19.0) & 17 & $(81.0)$ \\
\hline $\begin{array}{l}\text { RHOA- } \\
\text { Genotype }\end{array}$ & 396 & & & & & 0.203 & & & & 0.397 & & & & 0.789 \\
\hline Wildtype & 382 & (96.5) & 287 & $(75.1)$ & 95 & (24.9) & 244 & (63.9) & 138 & $(36.1)$ & 173 & $(45.3)$ & 209 & (54.7) \\
\hline Mutated & 14 & $(3.5)$ & 13 & (92.9) & 1 & (7.1) & 7 & $(50.0)$ & 7 & $(50.0)$ & 7 & $(50.0)$ & 7 & $(50.0)$ \\
\hline $\begin{array}{l}\text { GNAS1- } \\
\text { Genotype }\end{array}$ & 440 & & & & & 0.086 & & & & 0.865 & & & & 1.000 \\
\hline Negative & 399 & (90.7) & 305 & (76.4) & 94 & $(23.6)$ & 251 & $(62.9)$ & 148 & $(37.1)$ & 183 & (45.9) & 216 & $(54.1)$ \\
\hline Positive & 41 & $(9.3)$ & 26 & $(63.4)$ & 15 & $(36.6)$ & 27 & $(65.9)$ & 14 & $(34.1)$ & 19 & $(46.3)$ & 22 & (53.7) \\
\hline $\begin{array}{l}\text { Overall } \\
\text { Survival } \\
\text { [Months] }\end{array}$ & & & & & & $0.028^{(1)}$ & & & & $<0.001^{(1)}$ & & & & $0.185^{(1)}$ \\
\hline $\begin{array}{l}\text { Total / } \\
\text { Events / } \\
\text { Censored }\end{array}$ & $451 /$ & / 98 & $344 /$ & $76 / 68$ & 107 & 77 / 30 & $291 /$ & $45 / 46$ & 160 & 108 / 52 & 209 / & $55 / 44$ & 242 & $88 / 54$ \\
\hline $\begin{array}{l}\text { Median } \\
\text { Survival }\end{array}$ & 15. & & & $=1.1$ & 18. & \pm 5.8 & 12. & 1.1 & & $6 \pm 3.9$ & 14. & 1.3 & & \pm 2.1 \\
\hline 95\% C.I. & 12.8 & & 12 & 16.7 & & 30.2 & 10.5 & 14.7 & & -30.2 & 11. & 16.7 & & -20.6 \\
\hline $\begin{array}{l}\text { Tumor } \\
\text { Specific } \\
\text { Survival } \\
\text { [Months] }\end{array}$ & & & & & & $0.018^{(2)}$ & & & & $<0.001^{(2)}$ & & & & $0.050^{(1,2)}$ \\
\hline $\begin{array}{l}\text { Total / } \\
\text { Events / } \\
\text { Censored }\end{array}$ & $421 / 2$ & / 133 & $319 /$ & 28 / 91 & 102 & $50 / 42$ & $269 /$ & $22 / 67$ & 152 & $86 / 66$ & $196 /$ & 45 / 51 & 225 & $143 / 82$ \\
\hline $\begin{array}{l}\text { Median } \\
\text { Survival }\end{array}$ & 16. & & & $=1.3$ & 25 & \pm 8.8 & 13. & $=1.1$ & & $5 \pm 5.0$ & 15. & $=1.6$ & & \pm 2.9 \\
\hline 95\% C.I. & 13.8 & 9.6 & 13 & 18.5 & & 42.2 & 11. & 15.7 & & -39.3 & 12. & 18.6 & & -23.6 \\
\hline
\end{tabular}

EBV denotes Epstein-Barr virus, MSI microsatellite instability;

(1) insignificant after multiple testing.

(2) Log-rank test was applied to survival analyses; all other Fisher's exact test. 

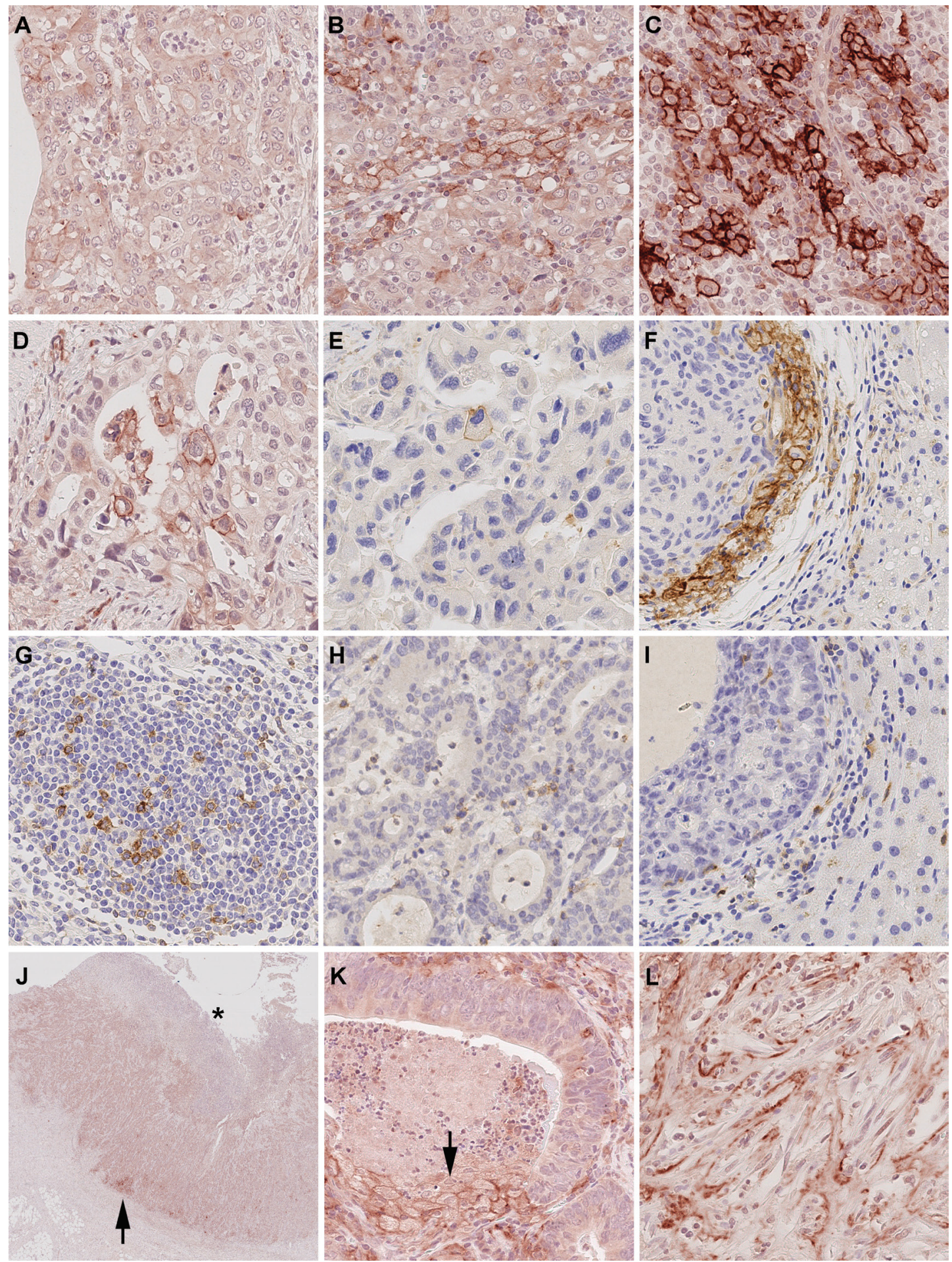

Figure 1: PD-L1 and PD-1 expression in gastric cancer and liver metastases. The entire gastric cancer (GC) cohort was screened and three representative cases were selected as reference slides for PD-L1 1+ A. 2+ B. and 3+C. PD-L1 expression was observed in primary GCs D. and its corresponding liver metastases E. Microsatellite instable GCs often showed an increased PD-L1 expression at the interface between tumor and non-neoplastic tissue, which could also be observed in GC liver metastases F. PD-1 positive lymphocytes were present in the majority of intratumoral lymph follicles G. PD-1 expression in diffuse tumor infiltrating lymphocytes (TILs; H.) correlated significantly with patient survival and was also observed in liver metastases I. PD-L1 positive tumor cells were close to the tumor surface (distance $<2.5 \mathrm{~mm}$, equivalent of an average biopsy forceps) and generally attainable by endoscopic biopsy $66.9 \%$. However, in 39 cases (33.1\%), PD-L1 positive tumor cells were localized only in the tumor center (J.; arrow head; the asterisk marks the mucosal surface) or near the invasion front. Necrotic tumor cells were found to show strong membranous PD-L1-expression (K.; arrow). PD-L1 positive stroma cells (L.) Original magnifications 2-fold J. and 400-fold (A-I., K-L.). 
Table 2: Distribution of PD-L1 expression in tumor cells for the entire cohort, GCs with distinct phenotypic and genotypic characteristics and Laurén subgroups

\begin{tabular}{|c|c|c|c|c|c|c|c|c|c|c|c|c|c|c|c|c|c|c|c|c|c|c|c|c|}
\hline \multirow{3}{*}{$\begin{array}{l}\text { Membranous PD-L1 } \\
\text { staining of tumor }\end{array}$} & \multicolumn{2}{|c|}{ Total } & \multicolumn{8}{|c|}{ PD-L1 Type } & \multicolumn{8}{|c|}{ Laurén phenotype } & \multicolumn{6}{|c|}{ Histology of MSI cases } \\
\hline & \multirow[b]{2}{*}{$\mathbf{n}$} & \multirow[b]{2}{*}{$(\%)$} & \multicolumn{2}{|c|}{$\begin{array}{c}\text { EBV } \\
\text { positive }\end{array}$} & \multicolumn{2}{|c|}{ MSI } & \multicolumn{2}{|c|}{$\begin{array}{l}\text { Papillary } \\
\text { type }\end{array}$} & \multicolumn{2}{|c|}{ Other } & \multicolumn{2}{|c|}{ Intestinal } & \multicolumn{2}{|c|}{ Diffuse } & \multicolumn{2}{|c|}{ Mixed } & \multicolumn{2}{|c|}{ Unclassified } & \multicolumn{2}{|c|}{$\begin{array}{c}\text { No } \\
\text { peculiarities }\end{array}$} & \multicolumn{2}{|c|}{$\begin{array}{c}\text { Single } \\
\text { peculiar } \\
\text { features }\end{array}$} & \multicolumn{2}{|c|}{$\begin{array}{l}\text { Highly } \\
\text { peculiar }\end{array}$} \\
\hline & & & $\mathbf{n}$ & $(\%)$ & $\mathbf{n}$ & $(\%)$ & $\mathbf{n}$ & $(\%)$ & $\mathbf{n}$ & $(\%)$ & $\mathbf{n}$ & $(\%)$ & $\mathbf{n}$ & $(\%)$ & $\mathbf{n}$ & $(\%)$ & $\mathbf{n}$ & $(\%)$ & $\mathbf{n}$ & $(\%)$ & $\mathbf{n}$ & $(\%)$ & $\mathbf{n}$ & $(\%)$ \\
\hline \multicolumn{25}{|l|}{ PD-L1 Quantity Score } \\
\hline $0(0 \%)$ & 325 & $(69.9)$ & 1 & $(5.0)$ & 16 & $(44.4)$ & 7 & $(23.3)$ & 282 & $(78.3)$ & 149 & $(62.1)$ & 133 & $(91.7)$ & 27 & $(87.1)$ & 15 & $(31.2)$ & 10 & $(76.9)$ & 5 & $(71.4)$ & 0 & $(0)$ \\
\hline $1(<=1 \%)$ & 80 & $(17.2)$ & 3 & $(15.0)$ & 5 & $(13.9)$ & 14 & $(46.7)$ & 58 & $(16.1)$ & 57 & $(23.8)$ & 7 & $(4.8)$ & 2 & $(6.5)$ & 14 & $(29.2)$ & 1 & $(7.7)$ & 0 & $(0)$ & 2 & (16.7) \\
\hline $2(2 \%-10 \%)$ & 47 & (10.1) & 9 & $(45.0)$ & 12 & $(33.3)$ & 9 & $(30.0)$ & 17 & $(4.7)$ & 29 & (12.1) & 4 & $(2.8)$ & 2 & (6.5) & 12 & $(25.0)$ & 2 & (15.4) & 2 & $(28.6)$ & 7 & $(58.3)$ \\
\hline $3(11 \%-50 \%)$ & 10 & $(2.2)$ & 5 & $(25.0)$ & 2 & $(5.6)$ & 0 & $(0)$ & 3 & $(0.8)$ & 3 & $(1.2)$ & 1 & $(0.7)$ & 0 & $(0)$ & 6 & (12.5) & 0 & $(0)$ & 0 & $(0)$ & 2 & (16.7) \\
\hline $4(>50 \%)$ & 3 & $(0.6)$ & 2 & $(10.0)$ & 1 & $(2.8)$ & 0 & (0) & 0 & $(0)$ & 2 & $(0.8)$ & 0 & $(0)$ & 0 & $(0)$ & 1 & $(2.1)$ & 0 & $(0)$ & 0 & $(0)$ & 1 & $(8.3)$ \\
\hline Total & 465 & $(100)$ & 20 & $(100)$ & 36 & $(100)$ & 30 & $(100)$ & 360 & $(100)$ & 240 & $(100)$ & 145 & $(100)$ & 31 & $(100)$ & 48 & $(100)$ & 13 & $(100)$ & 7 & $(100)$ & 12 & $(100)$ \\
\hline $\begin{array}{l}\text { Total / Missing / } \\
\text { p-Value }^{(1)}\end{array}$ & & & \multicolumn{8}{|c|}{$446 / 19 /<0.001$} & & & & $464 / 1 /$ & $<<0$ & .001 & & & & $32 /$ & 433 & $3 /<0.00$ & & \\
\hline PD-L1 Intensity Score & & & & & & & & & & & & & & & & & & & & & & & & \\
\hline 0 (negative) & 325 & $(69.9)$ & 1 & $(5.0)$ & 16 & $(44.4)$ & 7 & $(23.3)$ & 282 & $(78.3)$ & 149 & $(62.1)$ & 133 & $(91.7)$ & 27 & $(87.1)$ & 15 & $(31.2)$ & 10 & $(76.9)$ & 5 & $(71.4)$ & 0 & $(0)$ \\
\hline 1 (weak) & 36 & $(7.7)$ & 2 & $(10.0)$ & 4 & $(11.1)$ & 9 & $(30.0)$ & 21 & $(5.8)$ & 27 & $(11.2)$ & 4 & $(2.8)$ & 0 & $(0)$ & 5 & $(10.4)$ & 2 & $(15.4)$ & 0 & $(0)$ & 1 & $(8.3)$ \\
\hline 2 (medium) & 88 & (18.9) & 12 & $(60.0)$ & 14 & $(38.9)$ & 14 & $(46.7)$ & 48 & $(13.3)$ & 58 & $(24.2)$ & 6 & $(4.1)$ & 3 & $(9.7)$ & 21 & $(43.8)$ & 1 & $(7.7)$ & 2 & $(28.6)$ & 9 & $(75.0)$ \\
\hline 3 (strong) & 16 & $(3.4)$ & 5 & $(25.0)$ & 2 & $(5.6)$ & 0 & (0) & 9 & $(2.5)$ & 6 & $(2.5)$ & 2 & (1.4) & 1 & $(3.2)$ & 7 & (14.6) & 0 & $(0)$ & 0 & $(0)$ & 2 & (16.7) \\
\hline Total & 465 & $(100)$ & 20 & $(100)$ & 36 & $(100)$ & 30 & (100) & 360 & $(100)$ & 240 & (100) & 145 & $(100)$ & 31 & $(100)$ & 48 & $(100)$ & 13 & $(100)$ & 7 & $(100)$ & 12 & (100) \\
\hline $\begin{array}{l}\text { Total / Missing / } \\
\text { p-Value }^{(1)}\end{array}$ & & & & & & $446 / 19$ & $9 /<0$ & 0.001 & & & & & & 464 / 1 / & $<<0$ & .001 & & & & $32 /$ & 433 & $3 /<0.00$ & & \\
\hline $\begin{array}{l}\text { PD-L1 IRS (Sum } \\
\text { Score) }^{(3)}\end{array}$ & & & & & & & & & & & & & & & & & & & & & & & & \\
\hline 0 & 325 & (69.9) & 1 & $(5.0)$ & 16 & $(44.4)$ & 7 & $(23.3)$ & 282 & $(78.3)$ & 149 & $(62.1)$ & 133 & $(91.7)$ & 27 & $(87.1)$ & 15 & $(31.2)$ & 10 & (76.9) & 5 & $(71.4)$ & 0 & $(0)$ \\
\hline 2 & 29 & $(6.2)$ & 1 & $(5.0)$ & 2 & $(5.6)$ & 7 & $(23.3)$ & 19 & $(5.3)$ & 21 & $(8.8)$ & 3 & $(2.1)$ & 0 & $(0)$ & 5 & (10.4) & 1 & $(7.7)$ & 0 & $(0)$ & 0 & $(0)$ \\
\hline 3 & 56 & (12.0) & 3 & $(15.0)$ & 5 & (13.9) & 9 & $(30.0)$ & 39 & (10.8) & 40 & (16.7) & 5 & $(3.4)$ & 2 & $(6.5)$ & 9 & (18.8) & 1 & (7.7) & 0 & $(0)$ & 3 & $(25.0)$ \\
\hline 4 & 36 & $(7.7)$ & 7 & $(35.0)$ & 10 & $(27.8)$ & 7 & (23.3) & 12 & (3.3) & 23 & $(9.6)$ & 2 & (1.4) & 1 & $(3.2)$ & 10 & (20.8) & 1 & $(7.7)$ & 2 & (28.6) & 6 & $(50.0)$ \\
\hline 5 & 11 & $(2.4)$ & 4 & $(20.0)$ & 1 & $(2.8)$ & 0 & $(0)$ & 6 & $(1.7)$ & 5 & $(2.1)$ & 1 & $(0.7)$ & 1 & $(3.2)$ & 4 & $(8.3)$ & 0 & $(0)$ & 0 & $(0)$ & 1 & $(8.3)$ \\
\hline 6 & 5 & $(1.1)$ & 2 & $(10.0)$ & 1 & $(2.8)$ & 0 & $(0)$ & 2 & $(0.6)$ & 0 & $(0)$ & 1 & $(0.7)$ & 0 & (0) & 4 & $(8.3)$ & 0 & $(0)$ & 0 & $(0)$ & 1 & $(8.3)$ \\
\hline 7 & 3 & $(0.6)$ & 2 & $(10.0)$ & 1 & $(2.8)$ & 0 & $(0)$ & 0 & $(0)$ & 2 & $(0.8)$ & 0 & $(0)$ & 0 & $(0)$ & 1 & $(2.1)$ & 0 & $(0)$ & 0 & $(0)$ & 1 & $(8.3)$ \\
\hline Total & 465 & $(100)$ & 20 & $(100)$ & 36 & $(100)$ & 30 & $(100)$ & 360 & $(100)$ & 240 & $(100)$ & 145 & $(100)$ & 31 & $(100)$ & 48 & $(100)$ & 13 & $(100)$ & 7 & $(100)$ & 12 & $(100)$ \\
\hline $\begin{array}{l}\text { Total / Missing / } \\
\text { p-Value }{ }^{(1)}\end{array}$ & & & & & & $446 / 19$ & $9 /<0$ & 0.001 & & & & & & $464 / 1 /$ & $/<0$ & .001 & & & & $32 /$ & / 43 & $3 / 0.001$ & & \\
\hline PD-L1 Status & & & & & & & & & & & & & & & & & & & & & & & & \\
\hline negative (IRS < = 2) & 354 & $(76.1)$ & 2 & $(10.0)$ & 18 & $(50.0)$ & 14 & $(46.7)$ & 301 & $(83.6)$ & 170 & $(70.8)$ & 136 & $(93.8)$ & 27 & $(87.1)$ & 20 & $(41.7)$ & 11 & $(84.6)$ & 5 & $(71.4)$ & 0 & $(0)$ \\
\hline positive (IRS > 2) & 111 & (23.9) & 18 & $(90.0)$ & 18 & $(50.0)$ & 16 & $(53.3)$ & 59 & $(16.4)$ & 70 & (29.2) & 9 & $(6.2)$ & 4 & (12.9) & 28 & $(58.3)$ & 2 & (15.4) & 2 & $(28.6)$ & 12 & $(100)$ \\
\hline Total & 465 & $(100)$ & 20 & $(100)$ & 36 & $(100)$ & 30 & $(100)$ & 360 & $(100)$ & 240 & $(100)$ & 145 & $(100)$ & 31 & $(100)$ & 48 & $(100)$ & 13 & $(100)$ & 7 & $(100)$ & 12 & $(100)$ \\
\hline $\begin{array}{l}\text { Total / Missing / } \\
\text { p-Value }^{(1)}\end{array}$ & & & & & & $446 / 19$ & $9 /<0$ & 0.001 & & & & & & $464 / 1 /$ & $1<0$ & .001 & & & & & 433 & $3 /<0.00$ & & \\
\hline
\end{tabular}

(1) Fisher's exact test; (2) Log-rank test; (3) Sum of Quantitiy Score and Intensity Score; n.c.: cannot be calculated; n.a.: no data available. 


\section{Clinico-pathological correlation}

\section{PD-L1}

PD-L1 expression in tumor cells correlated significantly with gender, tumor localization, Laurén and mucin phenotype, UICC-stage, lymph node ratio, EBV-, MSI-, Her2/neu- and PIK3CA-status. PD-L1
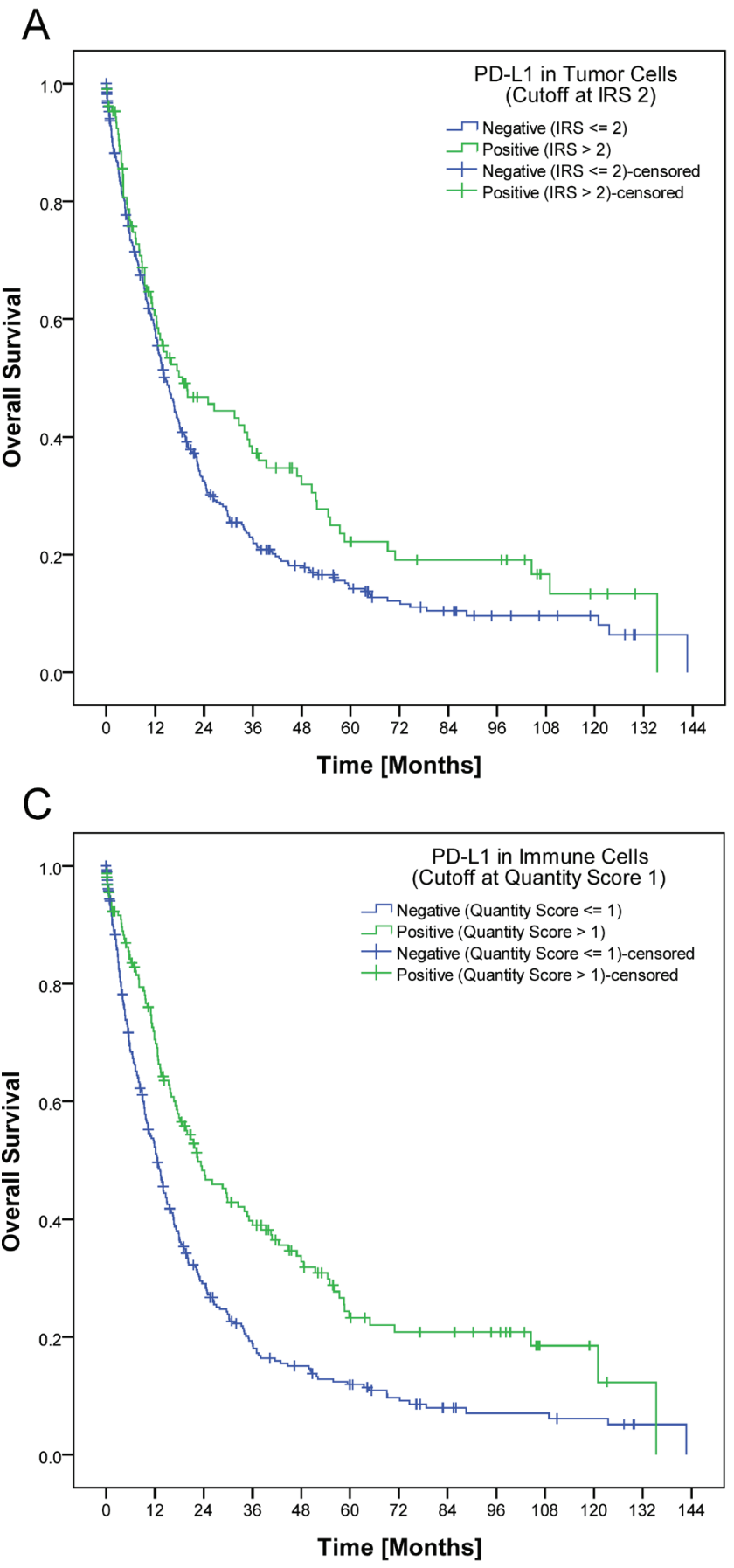

expression in immune cells correlated significantly with T-, M- and L-category, UICC-stage, EBV-, and PIK3CAstatus (Table 1). Interestingly, the percentage of PD-L1positive tumor and immune cells increased from pT1a to pT2 and decreased thereafter. No correlation was found between the PD-L1 expression in stroma cells and clinicopathological patient characteristics (data not shown).

B
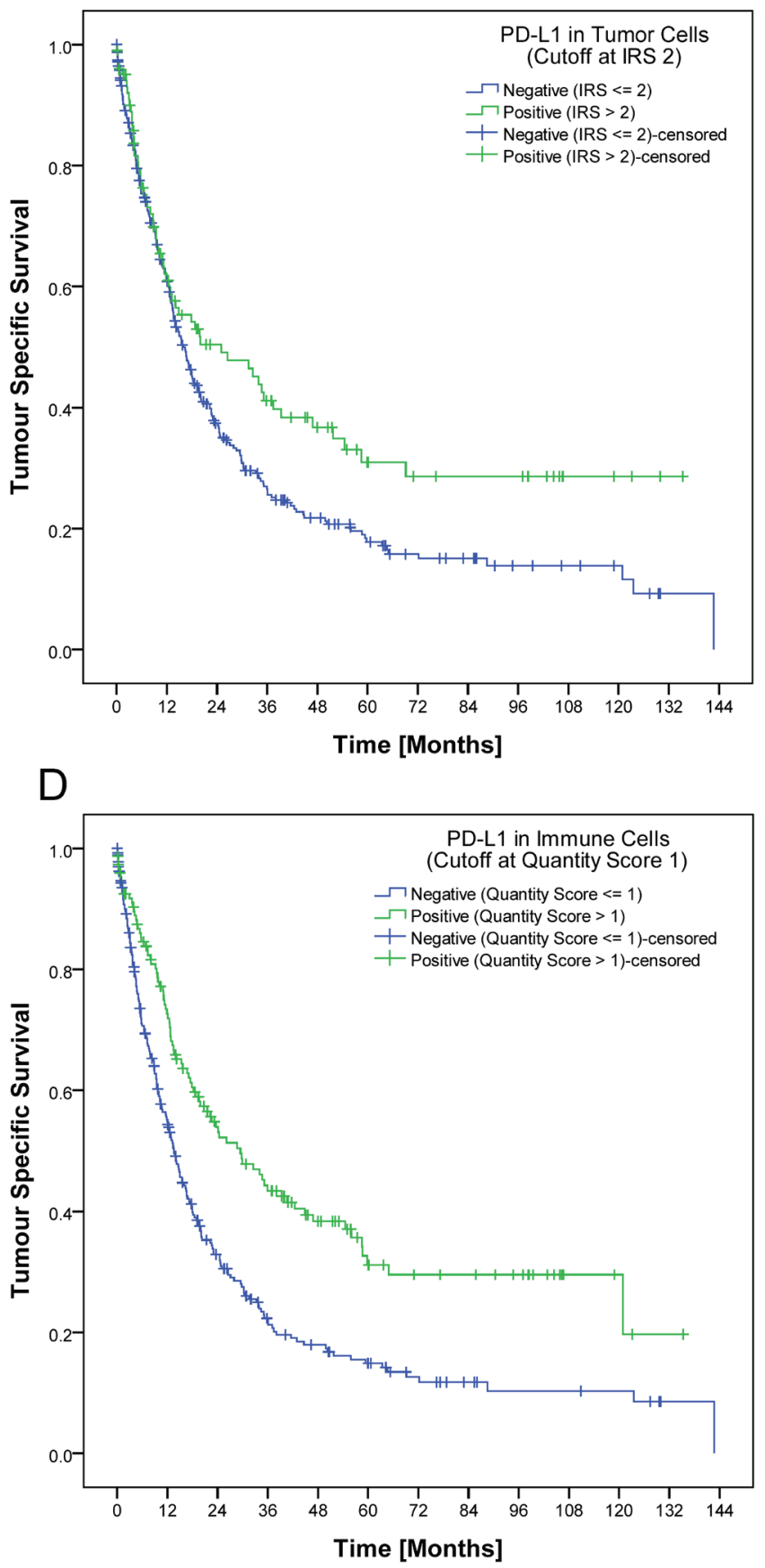

Figure 2: Development of a biomarker score. In our study, a tumor was regarded as PD-L1 positive if it had a least $2 \%$ tumor cells with an at least moderate membranous positivity IRS $(>2)$ respectively at least 10\% PD-L1 positive immune cells. Applying this cut-off, patients with PD-L1 positive tumor cells had a significant better overall $(\mathrm{p}=0.028 ;$ A.) and tumor specific survival $(\mathrm{p}=0.018$; B.). The same applied for patients with PD-L1 positive immune cells. PD-L1 expression in immune cells was significantly associated with a better overall and tumor specific survival ( $\mathrm{p}<0.001 \mathrm{each}$; C., D.). 


\section{PD-1}

There was no significant correlation between the PD-1 expression in TILs and any clinico-pathological patient characteristic after Simes' multiple testing procedure (Table 1).

\section{Prognostic significance}

\section{Univariate survival analysis}

Patient prognosis significantly depended on several clinico-pathological parameters as well as on the PDL1 expression in tumor cells and immune cells. Patients with a high PD-L1 expression in tumor cells (IRS $>2$ ) or immune cells (group 2 and 3) showed a significant better overall and tumor specific survival (Figure 2A-2D; Table 1). This effect could not be reproduced if the IRS-cut off for tumor cells respectively the cut-off for immune cells was marked down to 0 (Supplementary File 2). The best overall and tumor specific survival was observed for those patients with a high PD-L1 expression in tumor cells and in immune cells (Figure 3A-3B). There was no significant correlation between PD-L1 expression in stroma cells and patient survival (data not shown). In general, PD-L1-status correlated highly significantly between tumor and immune cells, tumor and stroma cells, and immune and stroma cells $(\mathrm{p}<0.001$ each; Figure 3C).

Patients with PD-1 positive TILs showed a better tumor specific survival, which was not significant after Simes' multiple testing procedure (Table 1; Figure 3D).

\section{Multivariate survival analysis (Cox regression)}

A Cox regression was carried out on all parameters which had a $\mathrm{p}<0.1$ in univariate survival analysis, i.e. Laurén-phenotype, T-, N-, M-, L-, V-, and R-category, UICC-stage, lymph node ratio, tumor grade, MSI-, MET-, PD-L1- (tumor and immune cells), and PD-1status (immune cells). Five parameters remained in the Cox model after running the backward LR method with $\mathrm{p}_{\mathrm{in}}=0.05$ and $\mathrm{p}_{\text {out }}=0.10$. These were UICC-stage, lymph node ratio, R-status, MET-status and PD-L1 expression in immune cells (Table 3 ).

\section{Expression in liver metastases}

Tissue specimens from liver metastases were available in 15 cases. Nine metastases $(60 \%)$ showed a membranous PD-L1 expression of tumor cells, which was mainly limited to single cells and ranged from 0.1 to $3 \%$ respectively from $1+$ to $2+$ (Figure $1 \mathrm{D}-1 \mathrm{~F}$ ). Dichotomized by an IRS $>2,5$ cases were classified as "PD-L1 positive" in tumor cells. Twelve of 15 cases $(80 \%)$ showed concordant staining results for the primary and its corresponding metastasis $(\kappa=0.471 ; \mathrm{p}=0.032)$.

PD-L1 expression in immune cells was found in 11 metastases $(73.3 \%)$ and ranged from 1 to $10 \%$ (Figure 1I). Dichotomized by the $10 \%$ cut-off, one case $(6.7 \%)$ was classified as PD-L1 positive in immune cells. Twelve of 15 cases $(80 \%)$ showed concordant staining results for the $\mathrm{GC}$ and its corresponding metastasis $(\kappa=0.328 ; \mathrm{p}=0.086)$.

PD-1 positive TILs were present in 11 metastases (73.3\%). The expression in GCs and their corresponding metastases was concordant in 12 cases $(80 \%$; $\kappa=0.526$; $\mathrm{p}=0.039$; Supplementary File 3).

\section{Accessibility for biopsy diagnostics}

In a palliative setting, only tumor biopsies may be available for testing of a predictive biomarker. Thus we explored the spatial distribution of PD-L1 positive tumor cells in the primary tumor. In 22 of 140 cases $(15.7 \%)$ with a membranous PD-L1 expression in tumor cells, the tumor surface could not be evaluated. In the remaining 118 cases, PD-L1 positive tumor cells were close to the mucosal surface and generally accessible by biopsy in 79 $(66.9 \%)$ cases. In 39 cases (33.1\%), PD-L1 positive tumor cells were localized only in the tumor center or near the invasion front (Figure 1J).

\section{DISCUSSION}

\section{PD-L1 and PD-1 are biologically and prognostically relevant in GC}

The present study is the first evaluation of PD-L1 and PD-1 expression in a large and well-characterized Caucasian cohort of GC. PD-L1 and PD-1 were expressed in a substantial amount of GCs either in tumor and immune cells or immune cells only. PD-L1 expression was found to be an independent survival prognosticator and correlated with distinct clinico-pathological patient characteristics.

Up to now, only five studies of smaller Asian patient cohorts investigated the PD-L1/PD-1 expression in GC [12-16]. PD-L1 was found in 43 to $63 \%$ of the Asian patients and, different from our cohort, showed a negative impact on patient survival. However, Asian and non-Asian GCs exhibit distinct tumor immunity signatures related to T-cell function [10], which may also affect the correlation of PD-L1/PD-1 expression with patient survival. In other tumor entities like malignant melanoma or lung cancer, it is proven that PD-L1 positive tumors show significant higher response rates to anti-PD-1/PD-L1 therapy. Thus, treatment independent effects on patient survival have to be considered in PD-L1/PD-1-positive GCs and have to be distinguished from therapeutic effects. Still, PD-L1/ PD-1 expression might serve as a predictive biomarker for PD-1/PD-L1 checkpoint inhibitor treatment, which raises several questions: What needs to be considered in the development of a PD-L1 biomarker score? Is it possible to reliably evaluate the PDL1/PD-1 expression by a biopsy? Which clinico-pathological patient characteristics may 
serve as a surrogate marker for PD-L1/PD-1-expression, in order to minimize the risk of sampling errors, e.g. in a palliative setting?

A

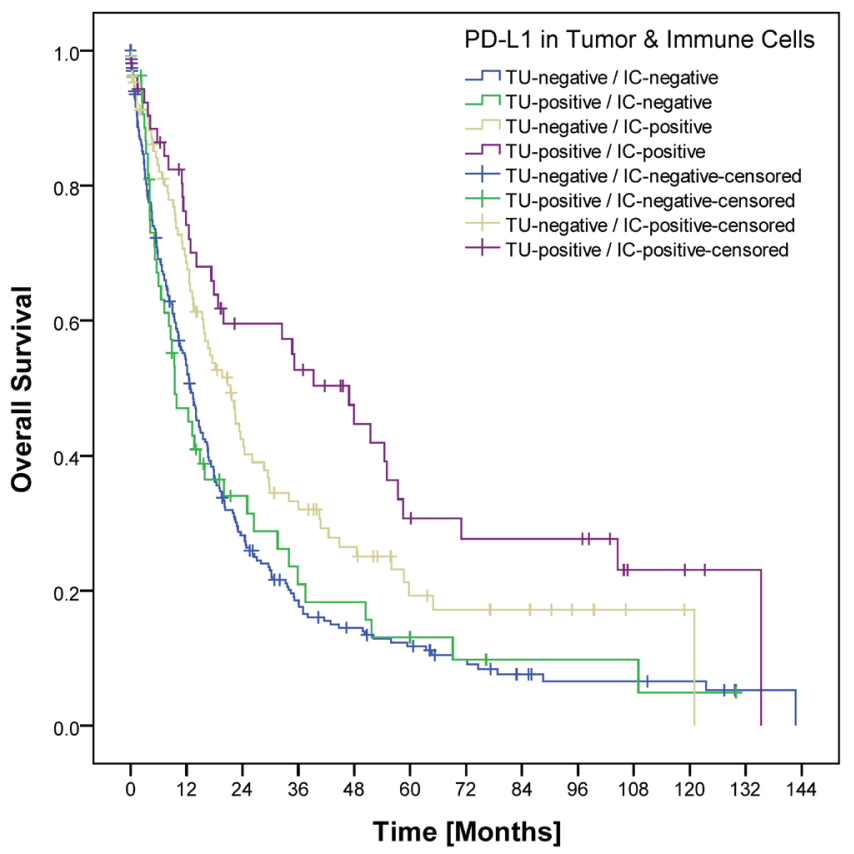

C

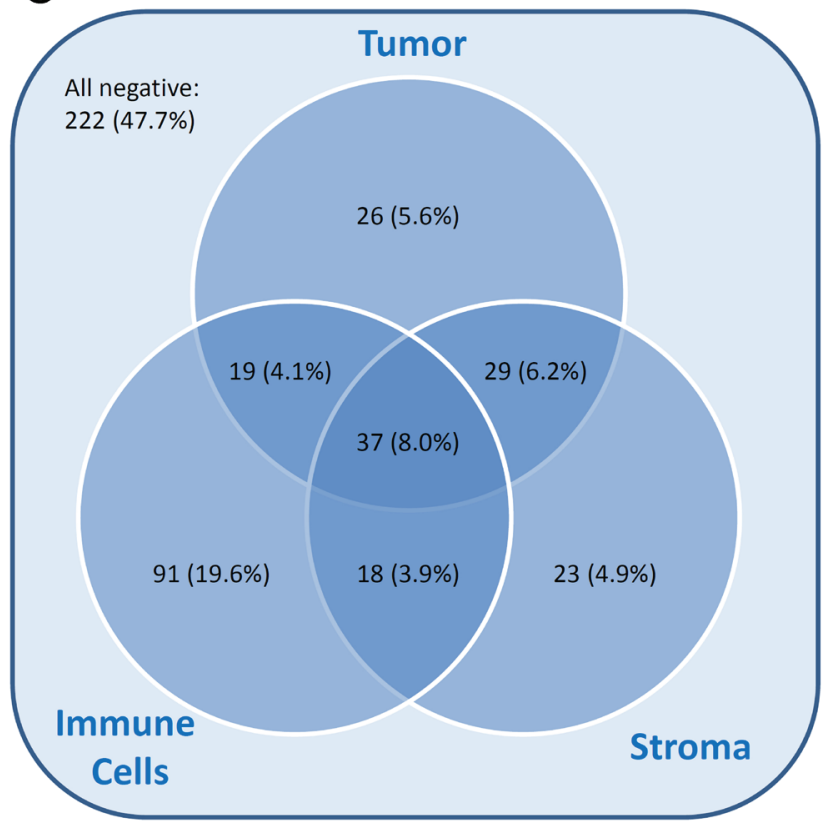

\section{PD-L1/PD-1 as putative predictive biomarkers}

Accurate interpretation of immunohistochemical stains is crucial for the establishment of a valid, histology-

B

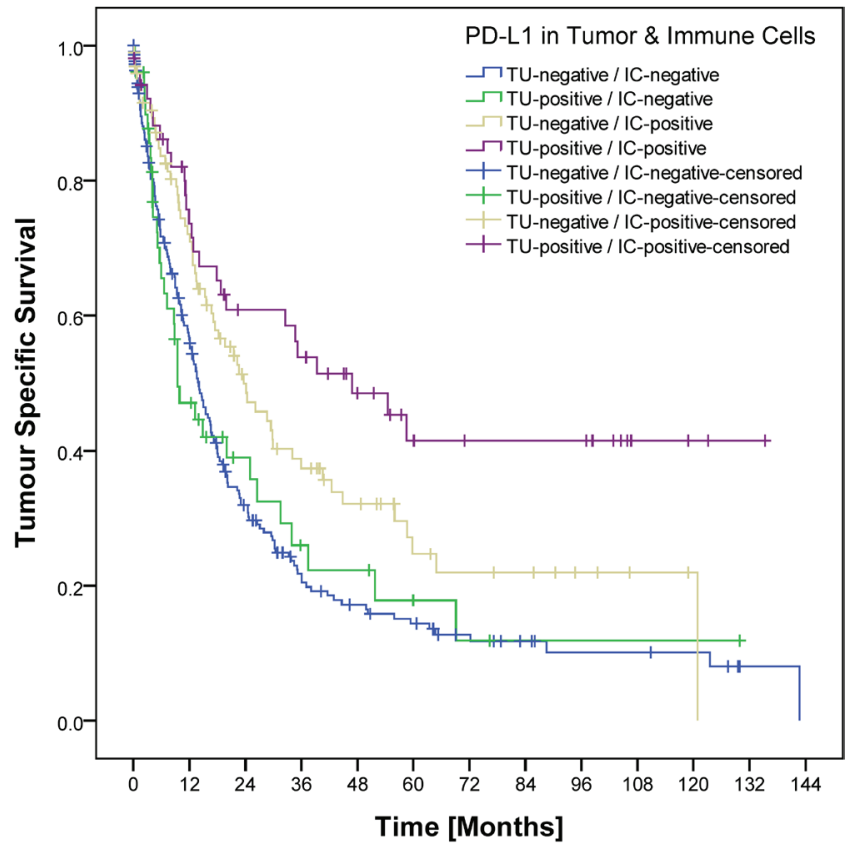

D

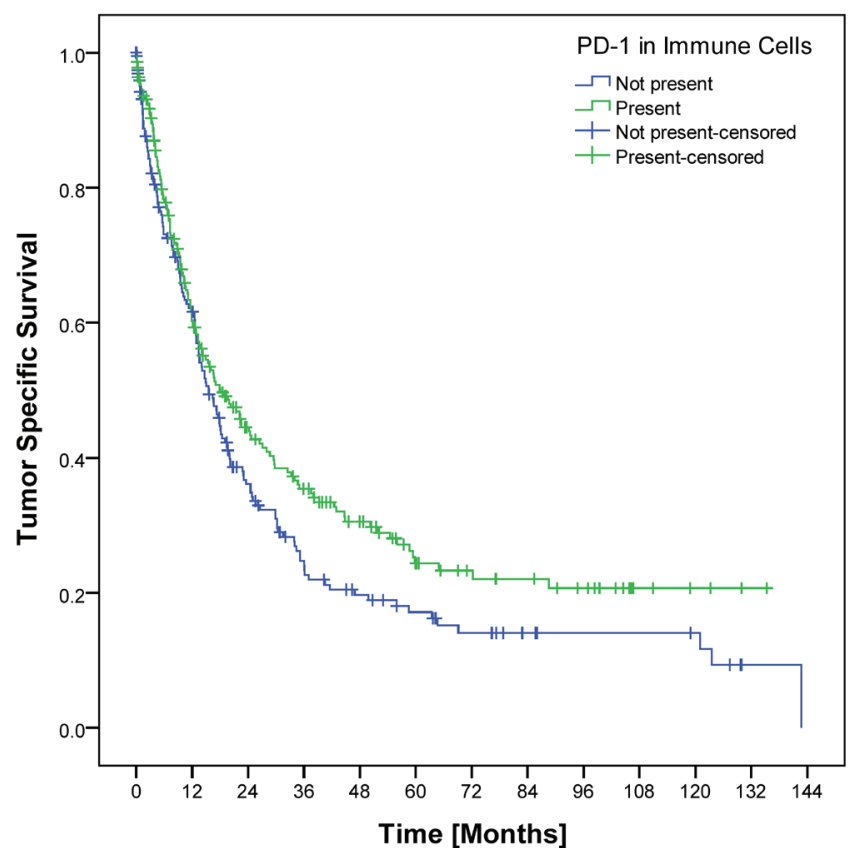

Figure 3: Prognostic significance and intersection of PD-L1 expression in tumor, immune and stromal cells. The best overall A. and tumor specific survival B. was observed for those patients with a high PD-L1 expression in tumor cells and in immune cells $(\mathrm{p}<0.001$ each). After grouping and dichotomization, 243 of 465 cases $(52.3 \%)$ were classified as "PD-L1 positive" for at least one tumor component (tumor cells, stroma cells and/or immune cells; C.). Expression in tumor cells, stroma cells and immune cells were significantly correlated with each other $(\mathrm{p}<0.001$ each). Patients with PD-1 positive TILs showed a better tumor specific survival, which was not significant after Simes' multiple testing procedure ( $\mathrm{p}=0.050 ;$ D.). 
Table 3: Univariate and multivariate survival analysis

\begin{tabular}{|c|c|c|c|c|c|c|c|c|c|c|c|c|}
\hline & \multicolumn{6}{|c|}{ Overall Survival } & \multicolumn{6}{|c|}{ Tumor Specific Survival } \\
\hline & \multicolumn{3}{|c|}{$\begin{array}{c}\text { Univariate Cox } \\
\text { Regression }\end{array}$} & \multicolumn{3}{|c|}{$\begin{array}{c}\text { Multivariate Cox } \\
\text { Regression* }\end{array}$} & \multicolumn{3}{|c|}{$\begin{array}{c}\text { Univariate Cox } \\
\text { Regression }\end{array}$} & \multicolumn{3}{|c|}{$\begin{array}{l}\text { Multivariate Cox } \\
\text { Regression* }\end{array}$} \\
\hline & HR & $\begin{array}{c}95 \% \\
\text { C.I. }\end{array}$ & p-Value & HR & $\begin{array}{l}\text { 95\% } \\
\text { C.I. }\end{array}$ & p-Value & HR & $\begin{array}{l}95 \% \\
\text { C.I. }\end{array}$ & p-Value & HR & $\begin{array}{l}\text { 95\% } \\
\text { C.I. }\end{array}$ & p-Value \\
\hline UICC-Stage & & & $<0.001$ & & & $<0.001$ & & & $<0.001$ & & & $<0.001$ \\
\hline IB vs. IA & 1.279 & $\begin{array}{l}0.614- \\
2.667\end{array}$ & 0.511 & 1.569 & $\begin{array}{l}0.685- \\
3.593\end{array}$ & 0.286 & 2.101 & $\begin{array}{c}0.782- \\
5.648\end{array}$ & 0.141 & 4.182 & $\begin{array}{l}1.102- \\
15.864\end{array}$ & 0.035 \\
\hline IIA vs. IA & 2.197 & $\begin{array}{l}1.221- \\
3.953\end{array}$ & 0.009 & 2.669 & $\begin{array}{l}1.352- \\
5.267\end{array}$ & 0.005 & 3.632 & $\begin{array}{l}1.572- \\
8.394\end{array}$ & 0.003 & 7.578 & $\begin{array}{l}2.273- \\
25.263\end{array}$ & 0.001 \\
\hline IIB vs. IA & 2.503 & $\begin{array}{l}1.357- \\
4.614\end{array}$ & 0.003 & 2.564 & $\begin{array}{l}1.268- \\
5.184\end{array}$ & 0.009 & 4.741 & $\begin{array}{l}2.046- \\
10.985\end{array}$ & $<0.001$ & 7.914 & $\begin{array}{l}2.371- \\
26.413\end{array}$ & 0.001 \\
\hline IIIA vs. IA & 3.874 & $\begin{array}{l}2.170- \\
6.915\end{array}$ & $<0.001$ & 3.249 & $\begin{array}{l}1.613- \\
6.544\end{array}$ & 0.001 & 6.925 & $\begin{array}{l}3.060- \\
15.674\end{array}$ & $<0.001$ & 9.145 & $\begin{array}{l}2.738- \\
30.543\end{array}$ & $<0.001$ \\
\hline IIIB vs. IA & 4.888 & $\begin{array}{l}2.816- \\
8.486\end{array}$ & $<0.001$ & 3.543 & $\begin{array}{l}1.766- \\
7.109\end{array}$ & $<0.001$ & 9.769 & $\begin{array}{l}4.435- \\
21.516\end{array}$ & $<0.001$ & 11.367 & $\begin{array}{l}3.411- \\
37.882\end{array}$ & $<0.001$ \\
\hline IIIC vs. IA & 7.918 & $\begin{array}{l}4.474- \\
14.014\end{array}$ & $<0.001$ & 5.217 & $\begin{array}{l}2.520- \\
10.801\end{array}$ & $<0.001$ & 15.184 & $\begin{array}{l}6.786- \\
33.971\end{array}$ & $<0.001$ & 15.248 & $\begin{array}{l}4.488- \\
51.807\end{array}$ & $<0.001$ \\
\hline IV vs. IA & 9.398 & $\begin{array}{l}5.416- \\
16.310\end{array}$ & $<0.001$ & 5.885 & $\begin{array}{l}2.900- \\
11.942\end{array}$ & $<0.001$ & 17.520 & $\begin{array}{l}7.945- \\
38.630\end{array}$ & $<0.001$ & 17.529 & $\begin{array}{l}5.226- \\
58.790\end{array}$ & $<0.001$ \\
\hline $\begin{array}{l}\text { LNR }>\text { Median } \\
(0.22)\end{array}$ & 3.044 & $\begin{array}{c}2.423- \\
3.825\end{array}$ & $<0.001$ & 1.698 & $\begin{array}{l}1.225- \\
2.353\end{array}$ & 0.001 & 3.475 & $\begin{array}{l}2.691- \\
4.487\end{array}$ & $<0.001$ & 1.684 & $\begin{array}{l}1.163- \\
2.438\end{array}$ & 0.006 \\
\hline R1/R2 vs. R0 & 3.701 & $\begin{array}{c}2.734- \\
5.012\end{array}$ & $<0.001$ & 2.243 & $\begin{array}{l}1.593- \\
3.158\end{array}$ & $<0.001$ & 4.220 & $\begin{array}{c}3.057- \\
5.826\end{array}$ & $<0.001$ & 2.544 & $\begin{array}{l}1.768- \\
3.661\end{array}$ & $<0.001$ \\
\hline MSI vs. MSS & 0.538 & $\begin{array}{c}0.342- \\
0.847\end{array}$ & 0.007 & & & & 0.384 & $\begin{array}{l}0.215- \\
0.686\end{array}$ & 0.001 & 0.541 & $\begin{array}{l}0.291- \\
1.005\end{array}$ & 0.052 \\
\hline MET positive & 2.826 & $\begin{array}{l}1.905- \\
4.193\end{array}$ & $<0.001$ & 2.324 & $\begin{array}{l}1.500- \\
3.600\end{array}$ & $<0.001$ & 2.841 & $\begin{array}{l}1.839- \\
4.387\end{array}$ & $<0.001$ & 2.385 & $\begin{array}{l}1.476- \\
3.853\end{array}$ & $<0.001$ \\
\hline $\begin{array}{l}\text { PD-L1 in tumor } \\
\text { cells }\end{array}$ & 0.753 & $\begin{array}{c}0.584- \\
0.971\end{array}$ & 0.029 & & & & 0.710 & $\begin{array}{c}0.533- \\
0.944\end{array}$ & 0.018 & & & \\
\hline $\begin{array}{l}\text { PD-L1 in } \\
\text { immune cells }\end{array}$ & 0.590 & $\begin{array}{l}0.470- \\
0.741\end{array}$ & $<0.001$ & 0.594 & $\begin{array}{l}0.461- \\
0.765\end{array}$ & $<0.001$ & 0.555 & $\begin{array}{l}0.431- \\
0.716\end{array}$ & $<0.001$ & 0.599 & $\begin{array}{c}0.451- \\
0.795\end{array}$ & $<0.001$ \\
\hline $\begin{array}{l}\text { PD-1 in } \\
\text { immune cells }\end{array}$ & & & & & & & 0.793 & $\begin{array}{l}0.629- \\
1.001\end{array}$ & 0.051 & & & \\
\hline
\end{tabular}

*Input variables: Laurén-phenotype, T-, N-, M-, L-, V- and R-category, UICC-stage, lymph node ratio, tumor grade, MSI-, MET-, PD-L1- (tumor and immune cells) and PD-1-status (immune cells).

LNR denotes lymph node ratio, MSI microsatellite instable and MSS microsatellite stable

based predictive biomarker. Although we aimed for the HistoScore, we recognized that the overall percentage of PD-L1-positive tumor cells was low and the assessment of different percentages of three different staining intensities was indiscernible and impractical. Applying our simplified IRS, we next used patient survival as surrogate marker for biological relevance. Interestingly, while dichotomization into completely negative and any positive staining of tumor cells did not show a significant correlation with patient survival (Supplementary File 2), dichotomization into PD-L1 IRS $\leq 1$ and $>2$ correlated significantly with patient survival (Figure 2). Thus, minimal expression of PD-L1 may have no effect on tumor biology. Similarly, only the presence of PD-1 positive diffusely distributed TILs, and not intratumoral lymph follicles, correlated significantly with patient survival. Based on our 
findings we suggest that a putative, PD-L1/PD-1-based immunohistochemical predictive biomarker score should not only explore tumor cells but also intratumoral immune cells.

\section{PD-L1 evaluation in biopsies carries the risk of sampling errors}

A significant number of patients is diagnosed at an advanced, inoperable stage [17]. Only biopsies might be available in these patients for biomarker testing. Our study shows that intratumoral heterogeneity also applies to PDL1 expression in GC: In 39 cases (33.1\%) PD-L1 positive tumor cells may not be sampled by a superficial biopsy. Accordingly, one third of PD-L1-positive GCs might carry the risk of a non-representative, i.e. false-negative, test result. This also may influence results of clinical trials exploring the value of PD-L1 as predictive biomarker in biopsy specimens.

In patients with a metastatic and/or unresectable GC, biopsy specimens might be obtained from the liver metastases, rather than the primary tumor, and biomarker expression between the primary GC and the liver metastasis might also show divergent test results. For Her2/neu, a discordance rate between 9 and 16\% is known [18]. In our study, PD-L1 and PD-1 were expressed in a significant portion of liver metastases, and concordant staining with the primary was found in $80 \%$. Yet, PD-L1/PD-1 positive GCs had PD-L1/PD-1 negative liver metastases, and vice versa. The presence of a PDL1 and PD-1 expression in liver metastases alone is an interesting finding, which might be relevant for clinical trials regarding immune checkpoint inhibitor treatment of metastatic disease. In this context, it was interesting to note that PD-L1-expression was high in pT2-tumors and lower in pT3 and pT4-tumours. Thus, PD-L1-expression may change during tumor progression, and analysis of liver metastases in PD-L1-negative primary GCs may be eligible.

\section{The association of PD-L1 expression with distinct phenotypes and genotypes might be helpful in the patient selection for a targeted PD-L1/PD-1 testing and therapy}

In view of non-representative tissue sampling issues, we were next interested to test the hypothesis whether other clinico-pathological patient characteristics may serve as surrogate markers for PD-L1/PD1-expression. Correlation of PD-L1/PD-1 expression with various clinico-pathological patient characteristics demonstrated that PD-L1 is enriched in men, intestinal, unclassified or papillary type GC of the proximal stomach, EBV-positive, and MSI GCs. The latter findings confirm independently previous observations $[1,19,20]$. EBV-positive GCs show a wide spectrum of histological characteristics but are often characterized by a marked lymphoid infiltration. MSI GCs predominantly consist of highly pleomorphic tumor cells, which are surrounded by a dense inflammatory stroma with little or no desmoplastic stroma reaction and often show pushing margins [21]. Thus, case selection may not only rely on immunohistochemical staining patterns, but also on distinct clinico-pathological characteristics thereby reducing the risk of sampling errors of biopsy specimens.

\section{The finding that PD-L1 expression is associated with the Her2/neu-status might open novel treatment strategies}

The simultaneous application of separate monoclonal antibodies (mAbs) or multi-specific mAbs is still in its infancies but might offer new treatment strategies for complex diseases [22]. Stagg et al. demonstrated the enhanced efficacy of anti-ErbB-2 with anti-PD-1 mAbin transgenic mice and thereby raised the possibility that anti-PD-1 mAb therapy could be used to capitalize on the immune-mediated effects of trastuzumab [23]. We found out that PD-L1-positive GCs hold a Her2/ neu-overexpression in nearly $50 \%$, which raises hopes that similar treatment strategies might be applicable in humans. In addition, PD-L1-expression correlated significantly with PIK3CA-mutational status and combination of PDL1/PD-1-targeted therapies with mTOR-inhibitors merit consideration in GC.

\section{Conclusion}

PD-L1 expression in GC of Western patients correlates significantly with overall and tumor specific survival as well as distinct clinico-pathological patient characteristics. Our findings might help to develop valid predictive test algorithms, which do not rely only on immunostaining patterns and may also help to explore novel combination therapies, e.g. trastuzumab or everolimus and PD-1/PD-L1 checkpoint inhibitors.

\section{MATERIALS AND METHODS}

\section{Ethics}

All procedures followed were in accordance with the ethical standards of the responsible committee on human experimentation (institutional and national) and with the Helsinki Declaration of 1964 and later versions. Informed consent or substitute for it was obtained from all patients for being included in the study. Ethical approval was obtained from the local ethical review board (D 453/10). 


\section{Study population}

From the archive of the Institute of Pathology, University Hospital Kiel, we sought Caucasian patients who had undergone either total or partial gastrectomy for adenocarcinoma of the stomach or esophago-gastric junction between 1997 and 2009. The following patient characteristics were retrieved: type of surgery, age at diagnosis, gender, tumor size, tumor localization, tumor type, tumor grade, depth of invasion, residual tumor status, number of lymph nodes resected, and number of lymph nodes with metastases. Patients were included if an adenocarcinoma of the stomach or esophagogastric junction was histologically confirmed. Exclusion criteria were defined as 1) histology identified a tumor type other than adenocarcinoma, and 2) patients had undergone a perioperative chemo- or radiotherapy. Each resected specimen had undergone gross sectioning and histological examination by trained and board certified surgical pathologists. Date of patient death was obtained from the Epidemiological Cancer Registry of the state of Schleswig-Holstein, Germany. Follow-up data of those patients who were still alive were retrieved from hospital records and general practitioners. All patient data were pseudonymized prior to study inclusion.

\section{Histology}

Tissue specimens were fixed in formalin and embedded in paraffin (FFPE). Deparaffinized sections were stained with hematoxylin and eosin. Histological reexamination of primary tissue sections was carried out for all cases to assure if inclusion criteria were met. Tumors were classified according to the Laurén classification [24] and re-examined by two surgical pathologists (CB, CR). pTNM-stage of all study patients was determined according to the $7^{\text {th }}$ edition of the UICC guidelines [25].

\section{Immunohistochemistry of PD-L1 and PD-1}

Immunostaining was carried out manually, using a rabbit monoclonal anti-PD-L1 antibody (1:75, E1L3N, CellSignaling, Danvers, United States of America). Tissue sections were pretreated in citrate buffer for antigen retrieval and incubated with hydrogen peroxide block and Ultra V Block (both Thermo Scientific, Braunschweig, Germany) to avoid unspecific reactions. For visualization the ImmPRESS-HRP-UniversalAntibody Polymer and the NovaRED substrate kit (both VectorLabs, Peterborough, United Kingdom) were applied. Counterstaining was done with hematoxylin (Dr. K. Hollborn \& Söhne GmbH \& Co KG; Leipzig, Germany). Immunohistochemical PD-L1 stainings of liver metastases and PD-1 stainings of GCs and liver metastases were carried out with a Bondmax automated slide staining system (Leica Biosystems, Wetzlar, Germany), using the
Polymer Refine Detection Kit (Menarini Diagnostics, Berlin, Germany) and the anti-PD-L1 antibody described above respectively a mouse monoclonal anti-PD-1antibody (clone MRQ-22, Cell Marque, Rocklin, United States of America). Germinal centers of lymph follicles served as internal positive control for both antibodies.

\section{Evaluation of immunostaining}

Intensity and percentage of stained cells was evaluated separately for tumor, stroma and immune cells by two pathologists (CB and $\mathrm{CR}$ ). For the evaluation of the PD-L1 expression in tumor cells, only the membranous staining was evaluated and the following immunoreactivity scoring system (IRS) was applied: Category A rated the percentage of immunoreactive cells and was graded as 0 (negative), 1 ( $\leq 1 \%$ positive), 2 ( 2 to $10 \%$ positive), 3 (11$50 \%)$ and $4(>50 \%)$. Category B documented the intensity of immunostaining as 0 (no immunostaining), 1 (weak), 2 (moderate), or 3 (strong). The addition of category A and $\mathrm{B}$ resulted in an IRS ranging from 0 to 7 . The evaluation of PD-L1 in stroma cells was rated as present or absent. For the evaluation of the PD-L1 expression in immune cells (lymphocytes, dendritic cells, macrophages), only the percentage of positive cells was considered, and cases were graded as 0 (negative), 1 (1-5\% positive), 2 (6-20\%) and 3 $(>20 \%)$. The immunostaining of PD-1 in immune cells was rated separately for tumor infiltrating lymphocytes (TILs) and intratumoral lymph follicles as present or absent.

\section{Immunohistochemistry, detection and assessment of phenotypic and genotypic characteristics}

The mucin phenotype, Helicobacter pylori-, Her2/ neu-, MET-, EBV-, MSI-status as well as the KRAS-, PIK3CA-, RHOA-, and GNAS-genotype was assessed as previously described [11, 21, 26-29].

\section{Study design}

Whole tissue sections from GCs and their liver metastases were stained with antibodies directed against PD-L1 and PD-1. The staining results were correlated with clinico-pathological and survival data.

\section{Statistical analysis}

Statistical analyses were done using SPSS 20.0 (IBM Corporation, New York, USA). For the evaluation of PD-L1 in tumor cells and immune cells, marker expressions were first examined as raw score values and then dichotomized into positive and negative. Cross tabulations of clinical data and marker expressions were tested for independence using Fisher's exact test. The correlation between the PD-L1 and PD-1 expression in 
GCs and corresponding metastases was calculated by using Cohen's kappa. A kappa value of 0.20 was considered to be poor, of $0.21-0.40$ to be fair, of $0.41-0.60$ to be moderate, of $0.61-0.80$ to be good, and of $0.81-1.00$ to be very good. Median overall and tumour specific survival were calculated using the Kaplan-Meier method. Logrank test was used to determine significance of differences between survival curves. Hazard ratios of variables were calculated by univariate Cox regression and those having p-values up to 0.1 were included in a multivariate Cox regression, combined with iterative backward LR method to identify independent prognostic variables. P-values up to 0.5 were considered as statistically significant. False discovery rate of correlations between clinical variables and biomarkers was controlled by applying the explorative Simes (Benjamini-Hochberg) procedure group-wise for each biomarker [30]. P-values are given unadjusted, but those having lost significance under the explorative Simes procedure are marked appropriately.

\section{ACKNOWLEDGMENTS}

We wish to thank Denisa Hajzeri for her excellent technical assistance.

\section{CONFLICTS OF INTEREST}

All authors declare that they have no conflicts of interest.

\section{GRANT SUPPORT}

CR is supported by grants of the German Research Foundation (Ro 1173/12).

\section{REFERENCES}

1. Cancer Genome Atlas Research Network. Comprehensive molecular characterization of gastric adenocarcinoma. Nature. 2014; 513: 202-209.

2. Wang K, Yuen ST, Xu J, Lee SP, Yan HH, Shi ST, Siu HC, Deng S, Chu KM, Law S, Chan KH, Chan AS, Tsui WY, et al. Whole-genome sequencing and comprehensive molecular profiling identify new driver mutations in gastric cancer. Nature Genetics. 2014; 46: 573-582.

3. Freeman GJ, Long AJ, Iwai Y, Bourque K, Chernova T, Nishimura H, Fitz LJ, Malenkovich N, Okazaki T, Byrne MC, Horton HF, Fouser L, Carter L, et al. Engagement of the PD-1 immunoinhibitory receptor by a novel B7 family member leads to negative regulation of lymphocyte activation. Journal of Experimental Medicine. 2000; 192: 1027-1034.

4. Keir ME, Butte MJ, Freeman GJ, Sharpe AH. PD-1 and its ligands in tolerance and immunity. Annual Review of Immunology. 2008; 26: 677-704.
5. Zou W, Chen L. Inhibitory B7-family molecules in the tumour microenvironment. Nature Reviews Immunology. 2008; 8: 467-477.

6. Poole RM. Pembrolizumab: first global approval. Drugs. 2014; 74: 1973-1981.

7. de Guillebon E, Roussille P, Frouin E, Tougeron D. Anti program death-1/anti program death-ligand 1 in digestive cancers. World Journal of Gastrointestinal Oncology. 2015; 7: 95-101.

8. Topalian SL, Hodi FS, Brahmer JR, Gettinger SN, Smith DC, McDermott DF, Powderly JD, Carvajal RD, Sosman JA, Atkins MB, Leming PD, Spigel DR, Antonia SJ, et al. Safety, activity, and immune correlates of anti-PD-1 antibody in cancer. The New England Journal of Medicine. 2012; 366: 2443-2454.

9. Alsina M, Moehler M, Hierro C, Guardeno R, Tabernero J. Immunotherapy for Gastric Cancer: A Focus on Immune Checkpoints. Targeted Oncology. 2016; doi: 10.1007/ s11523-016-0421-1.

10. Lin SJ, Gagnon-Bartsch JA, Tan IB, Earle S, Ruff L, Pettinger K, Ylstra B, van Grieken N, Rha SY, Chung $\mathrm{HC}$, Lee JS, Cheong JH, Noh SH, et al. Signatures of tumour immunity distinguish Asian and non-Asian gastric adenocarcinomas. Gut. 2015; 64: 1721-1731.

11. Metzger ML, Behrens HM, Boger C, Haag J, Kruger S, Rocken C. MET in gastric cancer - discarding a $10 \%$ cutoff rule. Histopathology. 2016; 68: 241-253.

12. Eto S, Yoshikawa K, Nishi M, Higashijima J, Tokunaga T, Nakao T, Kashihara H, Takasu C, Iwata T, Shimada M. Programmed cell death protein 1 expression is an independent prognostic factor in gastric cancer after curative resection. Gastric Cancer. 2015; doi: 10.1007/ s10120-015-0519-7.

13. Hou J, Yu Z, Xiang R, Li C, Wang L, Chen S, Li Q, Chen M, Wang L. Correlation between infiltration of FOXP3+ regulatory T cells and expression of B7-H1 in the tumor tissues of gastric cancer. Experimental Molecular Pathology. 2014; 96: 284-291.

14. Jiang D, Xu YY, Li F, Xu B, Zhang XG. The role of B7-H1 in gastric carcinoma: clinical significance and related mechanism. Medical Oncology. 2014; 31: 268.

15. Qing Y, Li Q, Ren T, Xia W, Peng Y, Liu GL, Luo H, Yang YX, Dai XY, Zhou SF, Wang D. Upregulation of PD-L1 and APE1 is associated with tumorigenesis and poor prognosis of gastric cancer. Journal of Drug Design, Development and Therapy. 2015; 9: 901-909.

16. Zhang L, Qiu M, Jin Y, Ji J, Li B, Wang X, Yan S, Xu R, Yang D. Programmed cell death ligand 1 (PD-L1) expression on gastric cancer and its relationship with clinicopathologic factors. International Journal of Clinical and Experimental Pathology. 2015; 8: 11084-11091.

17. Wagner AD, Unverzagt S, Grothe W, Kleber G, Grothey A, Haerting J, Fleig WE. Chemotherapy for advanced gastric 
cancer. Cochrane Database of Systematic Reviews. 2010; CD004064.

18. Gumusay O, Benekli M, Ekinci O, Baykara M, Ozet A, Coskun U, Demirci U, Uner A, Dursun A, Atak EY, Buyukberber S. Discordances in HER2 status between primary gastric cancer and corresponding metastatic sites. Japanese Journal of Clinical Oncology. 2015; 45: 416-421.

19. Gulley ML. Genomic assays for Epstein-Barr virus-positive gastric adenocarcinoma. Experimental and Molecular Medicine. 2015; 47: e134.

20. Le DT, Uram JN, Wang H, Bartlett BR, Kemberling $\mathrm{H}$, Eyring AD, Skora AD, Luber BS, Azad NS, Laheru D, Biedrzycki B, Donehower RC, Zaheer A, et al. PD-1 Blockade in Tumors with Mismatch-Repair Deficiency. The New England Journal of Medicine. 2015; 372: 2509-2520.

21. Mathiak M, Warneke VS, Behrens HM, Haag J, Böger C, Kruger S, Röcken C. Clinicopathologic Characteristics of Microsatellite Instable Gastric Carcinomas Revisited: Urgent Need for Standardization. Applied Immunohistochemistry and Molecular Morphology. 2015; doi: 10.1097/PAI.0000000000000264.

22. Li H, Sun Y, Chen D, Zhao H, Zhao M, Zhu X, Ke C, Zhang G, Jiang C, Zhang L, Zhang F, Wei H, Li W. Synergistic anti-tumor therapy by a comb-like multifunctional antibody nanoarray with exceptionally potent activity. Scientific Reports. 2015; 5: 15712.

23. Stagg J, Loi S, Divisekera U, Ngiow SF, Duret H, Yagita H, Teng MW, Smyth MJ. Anti-ErbB-2 mAb therapy requires type I and II interferons and synergizes with anti-PD-1 or
anti-CD137 mAb therapy. Proceedings of the National Academy of Science. 2011; 108: 7142-7147.

24. Lauren $T$. The two histologic main types of gastric carcinoma: Diffuse and so-called intestinal-type carcinoma. Acta Pathologica et Microbiologica Scandinavica. 1965;64: 31-49.

25. Sobin LH, Gospodarowicz M, Wittekind C. TNM Classification of Malignant Tumours. Wiley-Blackwell; 2009.

26. Böger C, Haag J, Egberts JH, Röcken C. Complex APC germline mutation associated metaplasia and intraepithelial neoplasia (CAM-IEN) of the gallbladder. Pathology Research and Practice. 2015; 212: 54-58.

27. Röcken C, Behrens HM, Böger C, Krüger S. Clinicopathological characteristics of RHOA mutations in a Central European gastric cancer cohort. Journal of Clinical Pathology. 2016; 69: 70-75.

28. Warneke VS, Behrens HM, Böger C, Becker T, Lordick F, Ebert MP, Röcken C. Her2/neu testing in gastric cancer: evaluating the risk of sampling errors. Annals of Oncology. 2013; 24: 725-733.

29. Warneke V, Behrens HM, Haag J, Balschun K, Böger C, Becker T, Ebert MP, Lordick F, Röcken C. Prognostic and putative predictive biomarkers of gastric cancer for personalized medicine. Diagnostic Molecular Pathology. 2013; 22: 127-137.

30. Benjamini Y. Discovering the false discovery rate. Journal of the Royal Statistical Society: Series B (Statistical Methodology). 2010; 72: 405-416. 